\title{
Tailor-Made Psychosocial Intervention for the Caregivers in Emergency and Trauma Care Center
}

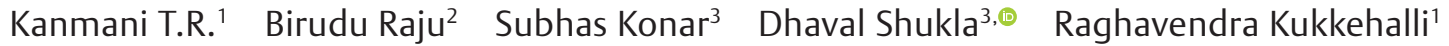 \\ ${ }^{1}$ Department of Psychiatric Social Work, National Institute of \\ Mental Health and Neurosciences, Bengaluru, Karnataka, India \\ ${ }^{2}$ Department of Social Work, Kristu Jayanti College, Bengaluru, \\ Karnataka, India \\ ${ }^{3}$ Department of Neurosurgery, National Institute of Mental Health \\ Address for correspondence Kanmani T.R, PhD, Department of \\ Psychiatric Social Work, National Institute of Mental Health and \\ Neurosciences, Bengaluru, Karnataka, India \\ (e-mail: kanmani.raju@gmail.com).
} and Neurosciences, Bengaluru, Karnataka, India

J Neurosci Rural Pract 2021;12:290-294.

\begin{abstract}
Keywords

- caregivers

- psychosocial problems

- intervention

Introduction The caregiver's psychosocial problems are unnoticed in the emergency and trauma care center. Therefore, the study objective was to understand the impact of psychoeducation and psychosocial intervention on traumatic brain injury (TBI) caregivers during hospitalization.

Methodology The study adopted a descriptive research design. Sixty-three $(n=63)$ consented caregivers were recruited by using a cross-sectional survey method. Two separate checklists were used to collect the psychosocial problems in emergency and trauma care as well as to know the satisfaction levels of caregivers after the intervention. $R$ free 3.0.1 software was used to calculate the frequency and percentage.

Results The caregiver's mean age was 39 years (39.46 \pm 16.22$)$. The majority of the caregivers were males $(45 ; 71.4 \%$ ) working as daily wagers $(42 ; 66.7 \%)$. Caregivers experienced psychosocial problems, that is, depression, anxiety, stress, unable to handle crisis, grief, lack of coping skills (57; 90.5\%), emotional distress (57; 90.5\%), financial constraints $(45 ; 71.1 \%)$, and need for referral services $(45 ; 71.1 \%)$. Tailor-made psychosocial interventions were provided to the caregivers.

Conclusion To conclude, there is a greater need to provide psychosocial intervention and train the caregivers to provide care for TBI survivors during hospitalization. There is a need to develop the uniform standard operating procedure for medical and psychiatric social workers in providing psychosocial care in emergency and trauma care setting.
\end{abstract}

\section{Introduction}

Traumatic brain injury (TBI) can result from a direct blow to the head or a blast injury following an explosion and can range from mild to severe. Over a period, TBI can result in possible cognitive problems, memory loss, impaired information processing, perceptual skills, communication deficits, and disability in patients that creates an emotional and financial burden on caregivers. ${ }^{1}$ Further, studies have highlighted TBI incident is more in the male population amounting to 30 to $40 \%$ severe; 70 to $90 \%$ survivors suffer from mild-to-moderate TBI, whereas better outcomes are observed in female patients. ${ }^{2-5}$ Thus, TBI survivors have complex needs that need to be met at the expense of family published online March 24, 2021
DOI https://doi.org/

10.1055/s-0041-1722815

ISSN 0976-3147. (c) 2021. Association for Helping Neurosurgical Sick People.

This is an open access article published by Thieme under the terms of the Creative Commons Attribution-NonDerivative-NonCommercial-License, permitting copying and reproduction so long as the original work is given appropriate credit. Contents may not be used for commercial purposes, or adapted, remixed, transformed or built upon. (https://creativecommons.org/licenses/by-nc-nd/4.0/).

Thieme Medical and Scientific Publishers Pvt. Ltd. A-12, 2nd Floor, Sector 2, Noida-201301 UP, India 
members. ${ }^{6}$ Family members often take caregiving role to look after persons with TBI after hospitalization. Based on the Indian research study, a caregiver is anyone who assists someone who is to some degree incapacitated and needs help. Among the Indian family system, the family owns the responsibility of providing care in the hospital in the process of recovery, functionality, and resource management. ${ }^{7}$

Assuming the primary caregiving responsibility for TBI survivors has resulted in depression, depression, anxiety distress, somatic symptoms, poor cohesiveness, and disturbances in family functioning. ${ }^{8-10}$ Informational needs and psychosocial problems of caregivers are unmet in emergency and trauma care setting. There is a need to educate caregivers, provide crisis intervention, and build stress management skills, which is the important role of medical and psychiatric social workers (MPSWs) in the trauma care setting. ${ }^{11-13}$ The key role of MPSWs includes providing psycho or neuroeducation, supportive intervention, case management, welfare measures, legal assistance, liaison services, home visits, and follow-up. ${ }^{14-16}$ Traumatic Brain Research and International Group of Researchers and Clinicians guidelines recommend that the health policies should aim to improve access to acute and postacute care to reduce the effects of TBI on patients, families, and society in a holistic approach by a specialized multidisciplinary team in liaison with patients, family, and caregivers. ${ }^{1,17}$ Despite guidelines in place, psychosocial interventional research and in the field of TBI, particularly on caregivers, is lacking in India. ${ }^{18}$ Therefore, the current study was aimed to understand the impact of psychoeducation on TBI caregivers during hospitalization in an emergency and trauma care setting.

\section{Methodology}

The present study adopted the descriptive research design, conducted in Emergency and Trauma Care Centre on a pilot basis, at the National Institute of Mental Health and Neurosciences, Bengaluru, India. Sixty-three caregivers were recruited purposively with predesigned inclusion and exclusion criteria. The inclusion and exclusion criteria as follow: adult caregivers age ranged from $>18$ to $<60$ years, who were providing care for TBI survivor at Head Injury Ward (HIW) at least more than a 1 week and those willing to participate were recruited after obtaining informed consent. In the process of sample recruitment, a total number of 80 caregivers were contacted at HIW of which $17(n=17)$ caregivers were not interested to take part in the study due to their reasons; hence, they were excluded. An extensive review of the literature search did not provide suitable scales to measure the psychosocial problems of TBI caregivers comprehensively. ${ }^{18}$ Therefore, field experts working in trauma care prepared a checklist, based on Indian literature, with yes or no options to capture the psychosocial problems and the components of psychoeducational interventions. Further, the checklist was divided into two parts. The first part consisted demographic details and psychosocial problems experienced by caregivers while providing care for TBI survivors covering various domains such as physical, psychological, emotional, social, and psychiatric symptoms. The second part consisted of questions related to feedback on the usefulness of psychoeducational interventions rendered to caregivers. Both the checklists were content validation by experts who were before administration on participants in terms of content, question framing, number of questions, and relevance of questions designed for caregivers.

The method of interventions used in this study was group psychoeducation and brief individual therapeutic interventions designed based on the needs of caregivers, review of the literature, and clinical experience in trauma care center published elsewhere. ${ }^{11,14,19,20}$ Systematic group psychoeducation focused on TBI illness, preadmission, predischarge counseling welfare benefits referral services, and linking within hospital and community resources. Individual therapeutic interventions focused on handling the TBI crisis, brief supportive, and grief therapy. Experts suggested that group psychoeducation would be the best method to provide information regarding head injury and TBI. Group psychoeducational was provided, a maximum of six sessions for 30 to 40 minutes. Each group consisted of six to seven members. Further, group members who reported to have severe psychological distress were identified for later individual therapeutic sessions on one to one basis as per the need.

Before the assessment of psychosocial problems, researchers had approached health care service providers (HCPs) such as neurosurgeons, nursing professionals, psychiatric social work consultants, and psychologists working in the trauma care setting. HCPs suggested a checklist that could measure the various psychosocial problems, brief group psychoeducation, and brief tailor-made therapeutic interventions would helpful considering the emergency environment, time constraints, caregivers workload, and emotional distress that caregivers undergo while caregiving at HIW. Experts also suggested that feedback could be collected to know whether psychoeducational interventions did benefit them or not. Based on the inputs given by experts, the checklist was prepared with yes or no responses aiming at measuring the various psychosocial problems, feedback form, and psychoeducational interventions that were developed accordingly to address the needs of caregivers.

$\mathrm{R}$ software was used to analyze the data. For nominal and categorical variables, frequency and percentages were calculated. Also, the chi-squared test was computed to find the associations between selected variables. Ethical clearance was obtained from the institute.

\section{Results}

A total number of 63 caregivers of TBI survivors diagnosed with subdural hematoma $(33 ; 52.4 \%)$, epidural hematoma $(25 ; 39.7 \%)$, and contusion $(5 ; 7.9 \%)$ participated in the study. The results showed the caregiver's mean age was 39 years (39.46 \pm 16.22$)$.

The majority of the caregivers were males 45 (71.4\%) and the rest 18 (28.6\%) were females. The majority of caregivers who had completed primary or secondary education were 45 (71.4\%), illiterate caregivers were 13 (20.6\%), and few caregivers studied up to graduation were only 5 (7.9\%). Further, results 
showed that 29 (46\%) the caregivers were parents, 22 (34.9\%) were spouses, and $12(19 \%)$ were significant family relatives. The majority of the caregivers worked as daily wagers (42; $66.7 \%$ ) and a few were working in private jobs $(21 ; 33.3 \%)$.

The present study findings revealed that all the caregivers (63; 100\%) had experienced informational and educational needs and 57 (90.5\%) caregivers experienced psychosocial problems, that is, depression, anxiety, stress, unable to handle crisis, grief, lack of coping skills, 57 (90.5\%) experienced emotional distress, 45 (71.1\%) caregivers experienced financial constraints and $45(71.1 \%)$ caregivers required referral services. - Table 1 depicts the caregiver demographic and psychosocial problems.

All the caregivers $(63 ; 100 \%)$ had received psychoeducation, $45(71.1 \%)$ had information about hospital services and existing resources, and 57 (90.5\%) received individual brief therapeutic intervention such as crisis interventions, grief intervention, supportive therapy, and coping skills. In addition, 45 caregivers (71.1\%) received preadmission counseling $(45 ; 71.1 \%)$ and $63(100 \%)$ availed predischarge counseling. Forty-five (71.1\%) caregivers received other types of services such as welfare benefits and referral services. - Table 2 indicates the percentage of psychoeducation and individual therapeutic interventions received by caregivers.

The chi-squared test results showed that there was significant association between gender and diagnosis $(\chi 2=6.932$; $\mathrm{df}=2 ; p<0.03)$; there was no significant association between gender and psychosocial problems $(\chi 2=3.662 ; \mathrm{df}=3 ; p<0.30)$ and diagnosis and psychosocial problems $(\chi 2=7.708 ; \mathrm{df}=6$; $p<0.26$ ). - Table 3 shows the chi-squared test results.

The feedback results showed that 63 (100\%) caregivers were satisfied with psychoeducation, 57 (90.5\%) were

Table 1 Demographic and psychosocial problems of caregivers of TBI

\begin{tabular}{|l|l|l|}
\hline Variable & Category & $\mathbf{n}(\%)$ \\
\hline \multirow{4}{*}{ Gender } & Male & $45(71.4)$ \\
\cline { 2 - 3 } & Female & $18(28.6)$ \\
\hline \multirow{4}{*}{ Education } & Illiterate & $13(20.6)$ \\
\cline { 2 - 3 } & Primary or secondary education & $45(71.4)$ \\
\cline { 2 - 3 } & Graduation & $5(7.9)$ \\
\hline \multirow{3}{*}{$\begin{array}{l}\text { Relationship } \\
\text { of caregivers }\end{array}$} & Daily wagers & $42(66.7)$ \\
\cline { 2 - 3 } & Private job & $21(33.3)$ \\
\cline { 2 - 3 } & Parents & $29(46)$ \\
\cline { 2 - 3 } $\begin{array}{l}\text { Psychosocial } \\
\text { problems }\end{array}$ & Significant others & $22(34.9)$ \\
\cline { 2 - 3 } & $\begin{array}{l}\text { Psychoeducational needs } \\
\text { Psychological problems } \\
\text { (depression, anxiety, stress, grief, }\end{array}$ & $63(100)$ \\
\hline & lack of coping) & $57(90.5 \%)$ \\
\cline { 2 - 3 } & Emotional distress & $45(71.1 \%)$ \\
\cline { 2 - 3 } & Financial constraints & $45(71.1 \%)$ \\
\cline { 2 - 3 } & $\begin{array}{l}\text { Need for referral services and } \\
\text { coordination with other hospitals }\end{array}$ \\
\hline
\end{tabular}

Abbreviation: TBI, traumatic brain injury. satisfied with the counseling services and therapeutic interventions, and 45 (71\%) caregiver mentioned that information regarding hospital resources and referrals services were useful and adequate to access the community resources. - Table 4 depicts the percentage of psychoeducation and individual therapeutic interventions.

Table 2 Percentage of need-based psychoeducational and therapeutic interventions provided

\begin{tabular}{|l|l|}
\hline Intervention & $\boldsymbol{n}(\%)$ \\
\hline Psychoeducation & $63(100 \%)$ \\
\hline Information on hospital resources & $45(71.1 \%)$ \\
\hline Crisis intervention & $57(90.5 \%)$ \\
\hline Grief intervention & $57(90.5 \%)$ \\
\hline Supportive therapy & $57(90.5 \%)$ \\
\hline Enhancing coping abilities & $57(90.5 \%)$ \\
\hline Preadmission counselling & $45(71.1 \%)$ \\
\hline Predischarge counselling & $63(100 \%)$ \\
\hline Assistance in accessing welfare benefits & $45(71.1 \%)$ \\
\hline $\begin{array}{l}\text { Referral services and coordinating with other } \\
\text { hospitals }\end{array}$ & $45(71.1 \%)$ \\
\hline
\end{tabular}

Table 3 Association between selected variables

\begin{tabular}{|l|l|l|l|}
\hline Variable & $\chi^{2}$ & df & $p<0.05^{\mathrm{a}}$ \\
\hline Gender and diagnosis & $6.932^{\mathrm{a}}$ & 2 & 0.031 \\
\hline $\begin{array}{l}\text { Gender and psychosocial } \\
\text { problems }\end{array}$ & $3.662^{\mathrm{a}}$ & 3 & 0.300 \\
\hline $\begin{array}{l}\text { Diagnosis and psychoso- } \\
\text { cial problems }\end{array}$ & $7.708^{\mathrm{a}}$ & 6 & 0.260 \\
\hline
\end{tabular}

${ }^{a} p<0.05$ set as significant value with $95 \%$ confidence interval.

Table 4 Feedback on psychoeducational and psychotherapeutic interventions

\begin{tabular}{|l|l|l|}
\hline Variable & Response & $\mathbf{n}(\%)$ \\
\hline $\begin{array}{l}\text { Does the information provide about } \\
\text { services and resources within the hospital } \\
\text { useful? }\end{array}$ & Yes & $45(71.1)$ \\
\cline { 2 - 3 } & No & $18(28.6)$ \\
\hline $\begin{array}{l}\text { Is provided education about TBI } \\
\text { consequences and home care manage- } \\
\text { ment useful? }\end{array}$ & Yes & $63(100)$ \\
\cline { 2 - 3 } & No & 0 \\
\hline Are counseling services useful? & Yes & $57(90.5)$ \\
\cline { 2 - 3 } & No & $6(9.5)$ \\
\hline \multirow{2}{*}{ Is brief therapy useful? } & Yes & $57(90.5)$ \\
\cline { 2 - 3 } & No & $6(9.5)$ \\
\hline Were you satisfied with MPSWs services & Yes & $45(71.1)$ \\
\cline { 2 - 3 } rendered in accessing welfare benefits? & No & $18(28.6)$ \\
\hline Are you happy with referral services? & Yes & $45(71.1)$ \\
\cline { 2 - 3 } & No & $18(28.6)$ \\
\hline Are you satisfied with overall & Yes & $63(100)$ \\
\cline { 2 - 3 } interventions? & No & $0 \%$ \\
\hline
\end{tabular}

Abbreviations: MPSWs, medical and psychiatric social workers; TBI, traumatic brain injury. 


\section{Discussion}

In India, psychosocial interventional research on caregivers of TBI survivors is lacking. Hence, the present study significantly contributes to TBI-related research from a psychosocial perspective. The present study found the majority of the caregivers were males. Caregivers were mostly parents, spouses, and other relatives like in-laws and friends who had experienced high emotional distress, various degree of depression, anxiety, stress, crisis, grief, inability to cope with trauma, financial constraints and faced problems concerning lack of timely information. The chi-squared results further showed that there was no significant association between gender and psychosocial problems, diagnosis, and psychosocial problems in the current sample. Thus, it is evident that road traffic accident (RTA) caused TBI to harm the mental health of caregivers irrespective of gender. Previous studies have reported caregivers of TBI to undergo a higher percentage of depression, anxiety, stress while providing care for TBI survivors reported elsewhere. ${ }^{8-10}$ Caregiver's gender was associated with the diagnosis. Contusion, extradural hematoma, subarachnoid hemorrhage, and hematoma were commonly reported among females with better outcomes. Also, the occurrence of RTA is high among males compared with females. ${ }^{5,21}$ The study recommends further research exploring and identifying the disease-specific psychosocial problems in the field of RTA caused by TBI. In addition to that, the information and educational needs of TBI caregivers were unfilled. Caregivers were interested to know about the consequences of TBI and how to manage survivors at home.

Therefore, to meet the caregiver's various informational, educational, and psychological distress, tailor-made brief psychoeducational and psychotherapeutic interventions were provided in a structured manner. These brief psychosocial interventions seemed to be beneficial and improved the satisfaction level of caregivers during hospitalization. The study findings go in line with earlier studies that have reported psychosocial interventions are helpful to meet the various educational needs and reduce the psychological distress among caregivers. Social work interventions that were offered for TBI families and caregivers helped to reduce the caregiver burden and increased satisfaction..$^{11,15,19,20}$ However, the psychosocial interventions should be tested in the stringent experimental environment to replicate in other settings preferably randomized control trials. Further research is warranted in this area.

Another finding of the current study was caregiver's inadequate knowledge regarding home care had resulted in having fear, apprehensions, and anxiety. This finding highlights the need for caregivers training during hospitalization and to meet long-term needs of TBI survivors. MPSWs who are working in the emergency and trauma care setting must take the lead role and initiate the caregiver structured training programs by collaborating with the trauma care team and mental health professionals by adhering to the international guidelines. ${ }^{118}$

The study had certain limitations in terms of small sample size, time constraints, brief psychoeducation, and therapeutic interventions that were provided. Further, the study did not apply standardized tools to measure the psychosocial problems of the caregivers. All the families that had accessed services in emergency and trauma care centers did not receive preadmission counseling due to nonavailability of MPSWs around the clock. Thus, there is a high need of appointing MPSWs in emergency and trauma care centers to meet the psychosocial needs of TBI survivors and caregivers on a $24 \times 7$ basis.

\section{Conclusion}

TBI survivors and caregivers undergo mental health problems besides informational and educational needs. Thus, appointing the mental health professionals especially MPSWs on a $24 \times 7$ basis is paramount to address the crisis, psychosocial problems, skill-building to the caregivers to meet the shortand long-term needs. It is also observed that structured psychosocial interventions are increased family satisfaction in emergency and trauma care centers. Therefore, there is a greater need to develop a uniform standard operating procedure to streamline and deliver psychosocial care in emergency and trauma care setting.

\section{Conflict of Interest}

None declared.

\section{References}

1 Maas AIR, Menon DK, Adelson PD, et al; InTBIR Participants and Investigators. Traumatic brain injury: integrated approaches to improve prevention, clinical care, and research. Lancet Neurol 2017;16(12):987-1048

2 Hay J, Johnson VE, Smith DH, Stewart W. Chronic traumatic encephalopathy: the neuropathological legacy of traumatic brain injury. Annu Rev Pathol 2016;11:21-45

3 Te Ao B, Brown P, Tobias M, et al; BIONIC Study Group. Cost of traumatic brain injury in New Zealand: evidence from a population-based study. Neurology 2014;83(18):1645-1652

4 Das A, Botticello AL, Wylie GR, Radhakrishnan K. Neurologic disability: a hidden epidemic for India. Neurology 2012;79(21): 2146-2147

5 Farace E, Alves WM. Do women fare worse: a metaanalysis of gender differences in traumatic brain injury outcome. J Neurosurg 2000;93(4):539-545

6 Boschen K, Gargaro J, Gan C, Gerber G, Brandys C. Family interventions after acquired brain injury and other chronic conditions: a critical appraisal of the quality of the evidence. Neurorehabilitation 2007;22(1):19-41

7 Subodh BN, Nebhinani N. Caring for the family caregivers. Indian J Soc Psychiatry. 2016;32(1):1

8 Ennis N, Rosenbloom BN, Canzian S, Topolovec-Vranic J. Depression and anxiety in parent versus spouse caregivers of adult patients with traumatic brain injury: a systematic review. Neuropsychol Rehabil 2013;23(1):1-18

9 Kreutzer JS, Rapport LJ, Marwitz JH, et al. Caregivers' well-being after traumatic brain injury: a multicenter prospective investigation. Arch Phys Med Rehabil 2009;90(6):939-946

10 Sady MD, Sander AM, Clark AN, Sherer M, NakaseRichardson R, Malec JF. Relationship of preinjury caregiver and family functioning to community integration in adults with traumatic brain injury. Arch Phys Med Rehabil 2010; 91(10):1542-1550 
11 Raju B, Lukose S, Raj P, Reddy K. Clinically providing psycho-social care for caregivers in emergency and trauma care setting: scope for medical and psychiatric social workers. Int J Crit Illn Inj Sci 2016;6(4):206-210

12 Harding A. Safe haven laws. J Emerg Nurs 2009;35(4):352-353

13 Gupta A, Taly AB. Functional outcome following rehabilitation in chronic severe traumatic brain injury patients: a prospective study. Ann Indian Acad Neurol 2012;15(2):120-124

14 Albert SM, Im A, Brenner L, Smith M, Waxman R. Effect of a social work liaison program on family caregivers to people with brain injury. J Head Trauma Rehabil 2002;17(2):175-189

15 Shrivastava SR, Shrivastava PS, Ramasamy J. Medical social worker: Strengthening linkages between the hospital and the community. Int J Health Syst Disaster Manag. 2014;2(2):130

16 Birudu R, Reddy KN. Role of medical and psychiatric social workers in improving follow-up care in surgical settings: medical and psychiatric social work perspective. Int J Health Allied Sci 2018;7(2):120
17 Togher L, Wiseman-Hakes C, Douglas J, et al; INCOG Expert Panel. INCOG recommendations for management of cognition following traumatic brain injury, part IV: cognitive communication. J Head Trauma Rehabil 2014;29(4):353-368

18 Agrawal A, Munivenkatappa A, Shukla DP, et al. Traumatic brain injury related research in India: an overview of published literature. Int J Crit Illn Inj Sci 2016;6(2):65-69

19 Reddy NK, Vranda MN. Efficacy of family intervention in acquired head-injury cases in India. Disabil CBR Incl Dev 2012;23(3):137-149

20 Raju B, Reddy K. Are counseling services necessary for the surgical patients and their family members during hospitalization? J Neurosci Rural Pract 2017;8(1):114-117

21 Munivenkatappa A, Agrawal A, Shukla DP, Kumaraswamy D, Devi BI. Traumatic brain injury: does gender influence outcomes? Int J Crit Illn Inj Sci 2016;6(2):70-73 